\title{
Rate nephelometric determination of rheumatoid factor: comparison between Kallestad QM-300 and Beckman ICS-II (RF) methods
}

\author{
R J Collins, J C Neil, R J Wilson
}

\begin{abstract}
The Kallestad Corporation recently suggested that their new buffer system for the nephelometric detection of rheumatoid factor conferred advantages over existing systems. Two rate nephelometric procedures, the Kallestad QM-300 and the Beckman ICS-II (RF), were therefore compared. Sera $(n=157)$ were selected on the basis of a previous ICS-II value. The results on the QM-300 of sera with an initial rheumatoid factor value of $<\mathbf{4 0 0}$ IU identified two groups. Group 1 $(n=109)$ showed a good correlation with the ICS-II method while group $2(n=13)$ was highly discordant with the QM-300, producing significantly higher values. The values of 35 sera with an initial rheumatoid factor of $>\mathbf{4 0 0}$ IU were likewise highly discordant, with the QM-300 producing significantly lower values. Dilution recovery experiments implied that the Beckman buffer was likely to be contributory. As the formulae of the buffers remain proprietary, the reasons for the differences are speculative. The findings could be taken to indicate that the Kallestad value is a more accurate indicator of the quantity of rheumatoid factor than the Beckman value.
\end{abstract}

Since the original description of rheumatoid factor by Waaler ${ }^{1}$ and its documented clinical association with rheumatoid arthritis, ${ }^{2}$ the detection and quantitation of rheumatoid factor have been hallmarks in the differential diagnosis of autoimmune disease. Its demonstration is a major laboratory contribution to the American Rheumatism Association's diagnostic criteria for rheumatoid arthritis. ${ }^{3}$

Because of the clinical importance of rheumatoid factor, considerable attention has been directed to its accurate quantitation. Numerous methods have been used, including the principles of haemagglutination (RoseWaaler test $),{ }^{2}$ latex agglutination, ${ }^{4}$ complement fixation, ${ }^{5}$ radioimmunoassay, ${ }^{6}$ enzyme linked immunosorbent assay (ELISA) ${ }^{78}$ and endpoint ${ }^{9}$ and rate nephelometry. ${ }^{10-12}$ Recent quality assurance programmes show considerable interlaboratory variability in the detection of rheumatoid factor using manual procedures, ${ }^{1314}$ and it has been suggested that automated rate nephelometry has the precision and reproducibility to warrant its routine use in clinical practice. ${ }^{1214}$

Since nephelometry was first described ${ }^{15}$ several improvements in methodology have occurred, including the use of various polymers to enhance the antigen-antibody formation, ${ }^{16}$ and automation to monitor the rate of complex formation. ${ }^{17}$ As the Kallestad Diagnostic Corporation has recently suggested that its improved buffer system is advantageous in the detection of rheumatoid factor we compared their QM-300 Protein Analysis System (Kallestad, Austin, Texas) with the Beckman Auto Immunochemistry System ICS-II (RF) (Beckman Instruments Inc, Brea, California). ${ }^{11}$

\section{Methods}

Whole blood was collected by standard venepuncture technique using evacuated tubes (Beckton-Dickinson, Sunnyvale, California). After centrifugation $(1300 \times g$ for $10 \mathrm{~min}$ utes), serum was aliquoted $(2 \mathrm{ml})$ and stored at $-20^{\circ} \mathrm{C}$. All sera were heat inactivated at $56^{\circ} \mathrm{C}$ for 30 minutes and centrifuged at $8000 \times g$ for 10 minutes.

Rheumatoid factor was quantitated in all sera strictly according to the manufacturers' instructions.

Two groups of rheumatoid factor positive sera, selected on the basis of a previous ICS-II value, were studied. They consisted of 122 sera with rheumatoid factor values between 60 and $<400$ IU and 35 sera with rheumatoid factor values of $>400$ IU.

Within-run precision was determined by analysing up to 12 replicates of six sera. Between-run precision was determined by analysing four sera on both instruments on up to eight occasions. The instruments were

Table 1 Precision of determinations of six sera on QM-300 and ICS-II

\begin{tabular}{|c|c|c|c|c|c|c|c|c|c|c|c|c|}
\hline Instrument & $Q M-300$ & $I C S-I I$ & $Q M-300$ & $I C S-I I$ & $Q M-300$ & $I C S-I I$ & $Q M-300$ & $I C S-I I$ & $Q M-300$ & $I C S-I I$ & $Q M-300$ & $I C S-I I$ \\
\hline $\begin{array}{l}\mathrm{n}= \\
\text { Mean value } \\
1 \mathrm{SD} \\
\text { "CV }\end{array}$ & $\begin{array}{c}12 \\
77 \\
3 \\
3 \cdot 9\end{array}$ & $\begin{array}{c}12 \\
90 \\
4 \\
4 \cdot 4\end{array}$ & $\begin{array}{c}12 \\
84 \\
3 \\
3 \cdot 6\end{array}$ & $\begin{array}{c}12 \\
85 \\
3 \\
3 \cdot 5\end{array}$ & $\begin{array}{c}12 \\
137 \\
4 \\
2 \cdot 9\end{array}$ & $\begin{array}{r}12 \\
122 \\
6 \\
4.9\end{array}$ & $\begin{array}{c}12 \\
189 \\
4 \\
2 \cdot 1\end{array}$ & $\begin{array}{r}12 \\
228 \\
7 \\
3\end{array}$ & $\begin{array}{r}12 \\
853 \\
26 \\
3\end{array}$ & $\begin{array}{c}6 \\
1723 \\
24 \\
1.4\end{array}$ & $\begin{array}{c}12 \\
997 \\
18 \\
1 \cdot 8\end{array}$ & $\begin{array}{c}12 \\
1933 \\
54 \\
2 \cdot 8\end{array}$ \\
\hline
\end{tabular}


Table 2 Reproducibility of between-run determinations of four sera on QM-300 and ICS-II

\begin{tabular}{|c|c|c|c|c|c|c|c|c|}
\hline Instrument & $Q M-300$ & $I C S-I I$ & $Q M-300$ & $I C S-I I$ & $Q M-300$ & $I C S-I I$ & $Q M-300$ & $I C S-I I$ \\
\hline $\begin{array}{l}\mathrm{n}= \\
\text { Mean value } \\
1 \mathrm{SD} \\
{ }_{0} \mathrm{CV}\end{array}$ & $\begin{array}{c}7 \\
94 \\
5 \cdot 2 \\
5 \cdot 5\end{array}$ & $\begin{array}{c}7 \\
101 \\
11 \cdot 7 \\
11 \cdot 6\end{array}$ & $\begin{array}{c}7 \\
187 \\
15 \cdot 7 \\
8 \cdot 3\end{array}$ & $\begin{array}{c}7 \\
156 \\
17 \cdot 0 \\
11\end{array}$ & $\begin{array}{c}6 \\
273 \\
15 \cdot 5 \\
5 \cdot 7\end{array}$ & $\begin{array}{r}6 \\
266 \\
21 \cdot 4 \\
8 \cdot 0\end{array}$ & $\begin{array}{r}8 \\
1249 \\
30 \cdot 8 \\
2.5\end{array}$ & $\begin{array}{c}8 \\
1951 \\
80 \cdot 2 \\
4 \cdot 1\end{array}$ \\
\hline
\end{tabular}

Figure 1 Scattergram of values (IU) for 122 sera chosen on the basis of an initial ICS-II value of $<400$ IU. Two groups are identified; group $1(\mathbf{O})$, ICS-II rheumatoid factor values of $<400$ IU and $O M-300$ rheumatoid factor values of $<400 \mathrm{IU}$; and group 2 ( ), ICS-II values of $<400 I U$ and QM-300 rheumatoid factor values of $>400 \mathrm{IU}$. recalibrated at the beginning of each determination.

The rheumatoid factor binding characteristics and linear response range of each method were determined using 11 sera with rheumatoid factor values of $<400$ IU determined by both methods. The sera were manually diluted using precision pipettes from $1: 2$ to 1:10 with either Kallestad QM-300 diluent, Beckman buffer, or normal heat-inactivated serum (rheumatoid factor of $<60$ IU).

All statistical analyses of results from the two methods including means, standard deviations, Student's $t$ test for matched pairs, and linear regression were performed using the CSS statistical analysis software (Stattsoft Inc, Tulsa, Oklahoma).

\section{Results}

\section{PRECISION}

The rheumatoid factor values of the six sera examined for within-run precision ranged from $80 \mathrm{IU}$ to $1900 \mathrm{IU}$. The precision of both methods was high with the coefficient of variation (CV) being less than $5 \%$ over the entire range tested (table 1).

The rheumatoid factor values of the four sera examined for between-run precision ranged from 94 to $1951 \mathrm{IU}$. The CV for the QM-300 ranged from between $2.5 \%$ and $8.3 \%$ (mean $=5.5 \%$ ); the CV for the ICS-II ranged from between $4.1 \%$ and $11.6 \%$ $($ mean $=8.7 \%)($ table 2$)$.

SERA

Although the precision of both methods was high, significant differences in the rheumatoid factor values were shown by the two methods. With the QM-300, the results of 122 sera with initial ICS-II values of $<400$ IU identified two groups (fig 1). While the results of group 1 $(109$ sera) showed a good correlation $(r=0.906)$, the QM-300 values were significantly higher $(\mathrm{p}=0.01)$. Thirteen sera, however (group 2), gave highly discordant results. In group 2 there was no correlation between the values obtained by each method $(r=-0 \cdot 15)$, and the QM-300 values were significantly higher than the ICS-II results $(\mathrm{p}=0.000)($ table 3$)$.

While the results of the 35 sera, chosen with an initial ICS-II value of $>400 \mathrm{IU}$, showed good correlation $(\mathrm{r}=0.74)$, significant differences were again recorded, with the QM-300 producing lower values $(\mathrm{p}=0.000)$ (table 3).

\section{DILUTION RECOVERY EXPERIMENT}

All 11 sera examined produced similar dilution recovery curves (fig 2 ). The curves obtained for sera diluted with Beckman buffer and run on the ICS-II were significantly different from the curves of sera diluted with Kallestad buffer and run on the QM-300 and from the curves of sera diluted with normal human serum and run on both instruments $(p=0.0003$ at $1: 6$ dilution).

\section{Discussion}

The results of this study indicate that significantly different rheumatoid factor values can be obtained depending on which nephelometric system is used. There were several important findings.

Firstly, while the rheumatoid factor results for group 1, obtained using the Kallestad QM300 method, were significantly higher than those obtained using the Beckman ICS-II, the difference was of questionable clinical relevance.

Secondly, and of potential clinical relevance, are the findings associated with group 2 sera and all sera with rheumatoid factor values of $>400$ IU by both methods. Two apparently conflicting phenomena occurred. Some sera, whose reaction products neared the peak rate of light scatter, had significantly higher values ( $\mathrm{p}=0.000)$ determined by the QM-300 compared with the ICS-II system. All sera whose rheumatoid factor values were greater than 400 IU with the Beckman ICS-II system produced significantly lower values $(p=0.000)$ determined by the Kallestad QM-300.

These discrepancies are unlikely to be caused by the instrumentation itself as both instruments' precision and reproducibility are of a high standard. Our results implicate the Beckman buffer as the likely cause. Both in-

Table 3 Quantitation of rheumatoid factor in sera by

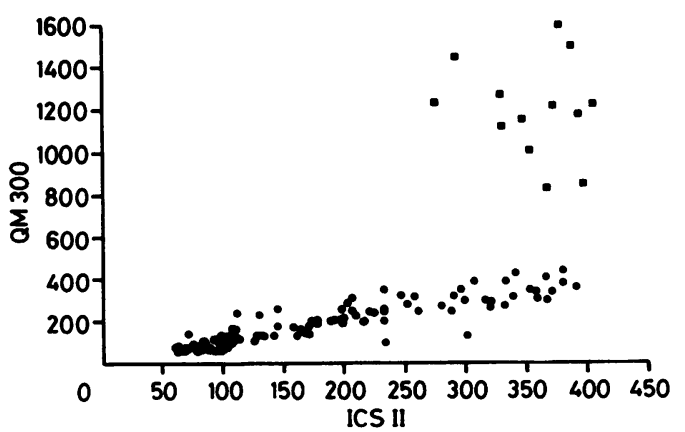

\begin{tabular}{|c|c|c|c|}
\hline & $I C S-I I$ & $Q M-300$ & \\
\hline & Mean (SD) & $\overline{M e a n}(S D)$ & $(n=)$ \\
\hline $\begin{array}{l}\text { ICS-II < } 400 \text { I.U. } \\
\text { Group } 1 \\
\text { Group } 2 \\
\text { ICS-II > } 400 \text { I.U. }\end{array}$ & $\begin{array}{c}178(97) \\
355(40) \\
2387(1266)\end{array}$ & $\begin{array}{c}189(103)^{\star} \\
1205(227)^{\dagger} \\
1380(703)^{+}\end{array}$ & $\begin{array}{r}109 \\
13 \\
35\end{array}$ \\
\hline
\end{tabular}




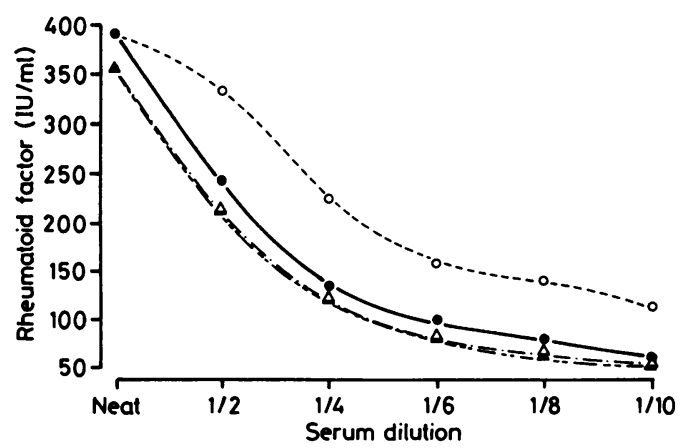

Figure 2 Dilution recovery experiments of a representative serum diluted with Beckman buffer (-) run on the ICS-II, or diluted with Kallestad Diluent $\triangle-\cdot-$ ) or normal human serum (- $-\ldots$ and run on the $O M-300$. At 1:6 dilution the rheumatoid factor values for sera $(n=11)$ diluted with Beckman buffer and run on the ICS-II are significantly higher $(p=0.0003)$ than the other combinations.

struments are automated and use a 1:6 dilution of sera to determine the rheumatoid factor value for sera whose peak rate light scatter is above a predetermined level. Our dilution recovery experiments show that the Beckman ICS-II system produces a higher value only when diluted in the Beckman buffer ( $\mathrm{p}=0.0003$ at $1: 6$ dilution). Results concordant with the Kallestad QM-300 value are obtained when sera are diluted with normal human serum. As the formulae of the buffers are proprietary, the reasons for the differences remain speculative. We interpret the findings, however, to indicate that the Kallestad method produces values which are a more accurate indication of the quantity of rheumatoid factor than the Beckman value. The clinical usefulness of a procedure which has the discriminatory power to identify patients of the group 2 category is yet to be determined. Furthermore, the findings have obvious implications for quality assurance programmes.
We thank Mrs C Ruetschi for assistance in the preparation of the manuscript, the physicians of the Royal Brisbane Hospital for referral of patients, and Ms L Druery and Ms F Battistutta for their technical assistance.

1 Waaler E. On the occurrence of a factor in human serum activating the specific agglutination of sheep blood corpuscles. Acta Pathol Microbiol Scand 1940;17:172-8.

2 Rose HM, Ragan C, Pearce E, Lipmann MO. Differential agglutination of normal and sensitised sheep erythrocytes by sera of patients with rheumatoid arthritis. Proc Soc Exp Biol Med 1948;68:1-11.

3 Arnett FC, Edworthy SM, Block DA, et al. The American Rheumatism Association 1987 revised criteria for the classification of rheumatoid arthritis. Arthritis Rheum 1988;31:315-24.

4 Singer JM, Plotz CM. The latex fixation test 1. Application to the serologic diagnosis of rheumatoid arthritis. $\mathrm{Am} \mathrm{J}$ Med 1956;21:888-92.

5 Taylor-Upsahl MM, Johnson PM, Mellbye OJ, Natvig JB. A study of complement fixation by rheumatoid factor using a haemolytic assay system. Clin Exp Immunol using a haemolyci

6 Quin JW, Giannikos J, Robertson P, Hand SJ. A simple radioactive binding assay for the detection of rheumatoid factor in serum. J Immunol Methods 1980;34:217-24.

7 Bampton JLM, Cawston TE, Kyle MV, Hazleman BL. Measurement of rheumatoid factors by an enzyme-linked immunosorbent assay (ELISA) and comparison with other methods. Ann Rheum Dis 1985;44:13-19.

8 Stone R, Coppock JS, Davies PT, et al. Clinical value of ELISA assays for IgM and IgG rheumatoid factors. J Clin Pathol 1987;40:107-11.

9 Weinblatt ME, Schur PH. Rheumatoid factor detection by nephelometry. Arthritis Rheum 1980;23:777-9.

10 Finley PR, Hicks MJ, Williams RJ, Hinlicky J, Lichti DA. Rate nephelometric measurement of rheumatoid factor in serum. Clin Chem 1979;25:1909-14.

11 Painter PC, Lyon JM, Evans JH, Powers WW, Wittaker RL, Decker MJ. Performance of a new rate nephelometric assay for rheumatoid factor, and its correlation with tubetiter results for human sera and synovial fluid. Clin Chem 1982;28:2214-18

12 Roberts-Thomson PJ, McEvoy R, Langhans T, Bradley J. Routine quantification of rheumatoid factor by rate nephelometry. Ann Rheum Dis 1985;44:379-83.

13 Rippey JH, Biesecker JL. Results of tests for rheumatoid factor on CAP survey specimen. Am J Clin Pathol 1983;80:599-602.

14 Roberts-Thomson PJ, Langhans T, McEvoy R, et al. SEAPAL quality control analysis of rheumatoid factor measurement in 29 diagnostic laboratories. Ann Rheum Dis 1987;46:417-20.

15 Gitlin D, Edelhoch H. A study of the reaction between human serum albumin and its homologous equine antibody through the medium of light scattering. $J$ Immunol 1951;66:67-77.

16 Lizana J, Hellsing K. Manual immunonephelometric assay of proteins with use of polymer enhancement. Clin Chem of proteins with

17 Buffone G, Savory J, Cross RE, Hammond JE. Evaluation of kinetic light scattering as an approach to the measurement of specific proteins with the centrifugal analyser. Immunology, methodology. Clin Chem 1977;21:1731-4. 